\title{
Using Tinbergen's Four Questions (Plus One) to Facilitate Evolution Education for Human-Oriented Disciplines
}

\author{
Daniel Tumminelli O'Brien • Andrew C. Gallup
}

Published online: 25 January 2011

(C) Springer Science+Business Media, LLC 2011

\begin{abstract}
Nikolaas Tinbergen provided an elegantly comprehensive guide to behavioral research with his Four Questions. Unsurprisingly, these questions summarize the different aspects that are vital to an evolutionary perspective. In this article, the authors describe how they use these Four Questions (plus one they have added regarding the role of culture) to facilitate evolution education in the human-oriented disciplines. The use of evolutionary theory in these fields is young, and educating new members of these fields in evolutionary theory is an even newer idea. Tinbergen's Four Questions (Plus One) make the goals of an evolutionary perspective clear and the application of the mechanisms of evolution apparent. It can effectively dispel myths that surround evolutionary theory, like genetic determinism and hyperadaptationism, and can help ameliorate other ideological concerns. Finally, it is suggested that it is a heuristic that encourages students to make the transition from understanding the mechanisms of evolution in biology to applying this knowledge in cross-disciplinary research.
\end{abstract}

Keywords Evolution education · Interdisciplinary approaches $\cdot$ Evolutionary psychology $\cdot$ Animal behavior

\footnotetext{
D. T. O’Brien $(\bowtie) \cdot$ A. C. Gallup

Department of Biology,

Binghamton University,

Binghamton, NY, USA

e-mail: Dobrien1@binghamton.edu

Present Address:

A. C. Gallup

Department of Ecology and Evolutionary Biology,

Princeton University,

Princeton, NJ 08544, USA
}

Nikolaas Tinbergen (1963) wrote that a thorough study in animal behavior must address four aspects of a trait: how it works, what function it serves, how it develops, and its phylogenetic history. Although not framed as explicitly evolutionary, Tinbergen's Four Questions, as they have since been dubbed, detail each major consideration an evolutionist might want to make. Due to its simplicity, the model is broadly accessible, and it can act as a clear window into what it means to take an evolutionary perspective for amateur and experienced scientists alike. In this paper, we describe how we have used a slightly modified version of Tinbergen's Four Questions (plus one question we have added) as a tool for teaching the application of evolutionary theory to human disciplines. Little formal curriculum work has been done in this area of evolution education, one that is plagued by a collection of common misconceptions. The Tinbergen model, however, not only makes the material more accessible but also provides an antidote for many of the myths that hinder the application of evolution to human behavior.

\section{Evolution and Human Affairs in the Classroom}

Following the visions of a handful of theorists (e.g., Gintis 2007; Wilson 2007), the application of evolutionary theory across the behavioral sciences has been a major breakthrough of the past two decades. Indeed, it has permeated a variety of fields, including psychology (e.g., Buss 2007), behavioral economics (e.g., Henrich et al. 2004), and literary theory (e.g., Carroll 2004). In addition, geneculture coevolution has provided a framework for simultaneously addressing genes and culture, two things whose study has long been housed by disparate disciplines that 
rarely communicate with each other (see Wilson 2007). As evolutionary theory continues to shed light on human behaviors and institutions, the implications are valuable to everyone, and useful to many in their professional lives, including teachers, lawyers, social workers, and doctors, to name a few. Unfortunately, undergraduate students rarely experience evolution outside of their courses in the biological sciences and are even less often encouraged to consider its application to their primary area of study.

In response to this shortfall, the Evolutionary Studies (EvoS) Consortium (http://evostudies.org/) has worked to develop formal curricula that educate students of all backgrounds in the application of evolutionary theory to human affairs. One of the most successful of these efforts has been Binghamton University's "Evolution for Everyone" (curriculum guide available in O'Brien and Wilson 2010). This introductory-level course attracts students from across all academic disciplines, and before-after surveys have demonstrated that students leave with an enhanced sense of evolutionary theory's application to the social sciences, humanities, and everyday life (O'Brien et al. 2009).

The authors have both been involved in teaching this course and have found that there are preexisting obstacles to educating students in the broader applications of evolutionary theory. The occasional student objects to evolutionary theory on the basis of Creationist or Intelligent Design reasoning; however, the elective nature of the course makes these individuals rare (O'Brien et al. 2009). Moreover, many students arrive with misconceptions about what it means to take an evolutionary perspective. It has been suggested that human examples can improve some aspects of evolutionary understanding by highlighting the importance of individual differences (Nettle 2010), but other difficulties do arise, including:

- Hyperadaptationism: After brief training in natural selection, many students equate an evolutionary perspective with being able to explain the presence of any trait in terms of functionality. If unchecked, this enthusiasm can lead to indiscriminate searches for adaptation and adherence to "just so" stories.

- Genetic determinism: Some enter the course with the perception that the debate between nature and nurture involves two irreconcilable sides and have no understanding of gene-environment interactions or phenotypic plasticity. They believe that for a given trait to be "genetic," there must be a fixed, immutable relationship between genotype and phenotype.

- Relativism: These two other misconceptions lead some students to fear that an evolutionary perspective will reduce all individual and cultural differences to adaptation and genetics. For those majoring in a social science or humanity, this deprives culture of its value and denies it any meaningful role in the purported "unification of the behavioral sciences."

\section{Tinbergen's Four Questions (Plus One)}

In this new area of education, there is the need to develop teaching techniques that illustrate an evolutionary perspective in such a way that makes the error of these impressions apparent. For reasons both of efficiency and grace, the authors feel that it is preferable to embed these issues in the main curriculum rather than discuss them as independent concerns. We have found that framing aspects of the course around Tinbergen's Four Questions (Plus One) accomplishes this in an elegant fashion by defining and distinguishing the main aspects of evolutionary inquiry. In turn, it provides a foundation for identifying interactions between these processes and relating these to the more complex phenomena that are observed in empirical research. As we summarize the components of Tinbergen's model, we provide specific human-oriented examples that illustrate each in Table 1.

Tinbergen's Four Questions begin with addressing the proximate mechanism, or, how does the trait work? This is

Table 1 Tinbergen's Four Questions (Plus one) with illustrative examples from a module on personality

\begin{tabular}{|c|c|c|}
\hline Question & Consideration & Example \\
\hline How does it work? & Proximate causation & $\begin{array}{l}\text { Male aggression levels are at least partially modulated by androgenic } \\
\text { hormones (Book et al. 2001) }\end{array}$ \\
\hline Why does it work? & Ultimate causation & $\begin{array}{l}\text { Extroverts have more mating success, but also run extra risks, } \\
\text { selecting for a balance between extro- and introversion (Nettle 2005) }\end{array}$ \\
\hline How does it develop? & Ontogeny & $\begin{array}{l}\text { One's place in the family hierarchy (i.e., birth order) can influence the } \\
\text { personality traits he or she adopts (Sulloway 1997) }\end{array}$ \\
\hline How did it evolve? & Phylogeny & $\begin{array}{l}\text { Aspects of the dopamine system modulate sensation seeking across } \\
\text { the animal kingdom (see Fidler et al. } 2007 \text { for evidence and a short review) }\end{array}$ \\
\hline What role does culture play? & Culture & $\begin{array}{l}\text { A more structured society may have selected for genes that code } \\
\text { for lower extroversion and impulsivity in China (Chang et al. 1996) }\end{array}$ \\
\hline
\end{tabular}


obviously the most basic of the questions and, without the others, is the general focus of atheoretical work. The second question is the ultimate mechanism, or, what function did it evolve to fill, or in response to what challenge did it evolve? Taken together, these first two describe the simplest of evolutionary questions: Why is the way something works adaptive?

The third question regards ontogeny, or what is the process and timing by which it develops? This question is instrumental in understanding the complexity of traits. When placed in conjunction with the other questions, it can be helpful in rebutting hyperadaptationism. When described in terms of gene-environment interactions, it provides a more sophisticated gene-to-phenotype relationship that some might call "the new genetic determinism" (Wilson 2007). We further elaborate on this utility below.

The fourth issue is that of phylogeny, or, what is the trait's deep evolutionary history? This question can occur at a number of different scales, and the appropriate one is determined by the aspect of the trait one is studying. For example, if one wants to understand the human eye, looking at this lens-like structure would require a study of vertebrate evolution. On the other hand, looking at the biochemical basis of its photosensitivity may involve analysis of ocular crystals throughout the animal kingdom.

Finally, as we have mentioned, we add our own fifth question to Tinbergen's model: What is the role of culture? This is clearly specific to the human condition as it can be argued that we are the only species in which culture is a pervading aspect of its environment (Richerson and Boyd 2004). It might seem that this could be subsumed piecemeal by the previous questions. Social learning (i.e., culture) is the process by which many traits function. Many cultural traits have an adaptive value within the local ecology. Culture is a feature of the environment and, like any other environmental characteristic, can influence development. Similarly, the inputs provided by culture can play an important role in the further evolution of genetic characteristics. For example, the domestication of cattle has led to genetic selection for lifelong lactose tolerance in northern Europeans (McCracken 1971).

Distinguishing these processes when they involve culture is quite valuable for two reasons. The first is a matter of communicating to an ideologically diverse population, many of whom are resistant to ignoring the exceptionality of human culture. Setting it apart in this fashion gives it the respect some feel it deserves, which then opens them to the possibility that it may play an important role in evolutionary research. The second is an empirical consideration. Culture is potentially the most elaborate example of a species modifying its own environment of which we are aware (Odling-Smee et al. 2003). Its direct relationship to our conscious, cognitive mechanisms endows it with a dynamic and, in some sense, goal-oriented relationship with the local environment, leading to implications for genetic evolution. There is a consistent feedback between these parallel lines of evolution, one that Richerson (2010) likens to a two-horse-drawn carriage. This model and its far-reaching implications are known as gene-culture coevolution (Richerson and Boyd 2004), offering a valuable alternative to cultural relativism.

To be clear, we are certainly not the first to employ Tinbergen's Four Questions in an educational setting. In fact, almost every case that the authors have found is itself an interdisciplinary field. For example, in their multiple volumes on behavioral ecology - a field that emphasizes the interplay between ultimate and proximate mechanisms in developmental processes-Krebs and Davies (e.g., 1993, 1997) invariably introduce the subject with Tinbergen's Four Questions. Likewise, in calling for the incorporation of evolutionary theory into medical curricula, Nesse and colleagues often invoke Tinbergen's model to make their case (Nesse et al. 2010; Nesse and Williams 1997). We are just the next in a long line of researcher-educators who see this approach as an effective way to bring the cutting-edge applications of evolutionary theory we use in our own work into our classrooms.

\section{Evolution for Everyone}

To contextualize the role of Tinbergen's Four Questions (Plus One) in Evolution for Everyone, we briefly summarize the course's curriculum and organization, information that is available in a more detailed fashion in O'Brien and Wilson (2010). We then describe how we incorporate Tinbergen's Four Questions (Plus One) by detailing how it is highlighted during a module on personality.

One of the course's secondary goals is to give students the tools to become everyday scientists; thus, the skills of scientific inquiry are woven into the course. In an effort to seamlessly merge this with the evolutionary curriculum, the course is explicitly structured around the sections of a scientific paper. Approximately the first third of the course, the "Introduction," focuses on the basic mechanisms of evolution, beginning with natural and sexual selection and continuing through more complex topics like phenotypic plasticity and coevolution. While learning this "background" information, students are also developing the skills necessary for writing an introduction: choosing a topic, conducting a literature review, and positing novel hypotheses. This is followed by the "Methods and Results" section in which we apply the mechanisms of evolution to a variety of topics in one- to two-week modules. Each module focuses on a specific topic (e.g., economics, personality) and consists of a lecture that connects relevant 
theory with human and non-human examples. Each includes a survey or experiment whose data are converted into a lecture illustrating how the consequences of evolution are visible in our own classroom. Through this, they gain exposure to basics in research methodology and statistical analysis. Below, we summarize the module on personality and how it is organized around Tinbergen's Four Questions (Plus One). Finally, the "Discussion" section takes the form of an end-of-semester poster session in which students propose novel research from an evolutionary perspective on a topic of their choice- a project they have been working toward throughout the semester.

We first highlight Tinbergen's Four Questions (Plus One) as the course transitions from the Introduction to the Methods and Results section. At this point, the students have been exposed to a relatively complete summary of the mechanisms of evolution and have seen all four of the questions in action. We distinguish between proximate and ultimate mechanisms in the first few lectures. Within the following two weeks, students have also received a lecture on phenotypic plasticity at a variety of levels, from developmental trajectories to moment-to-moment behavioral modulation. In addition, they receive one to two lectures on descent with modification and phylogenetic history. With this information in hand, the course shifts its attention to application, and the Tinbergen model allows students to distill and organize the material they have already learned into a guide for further inquiry.

Although others make Tinbergen's model the foundation of the curriculum from the outset (Krebs and Davies 1993, 1997; Nesse et al. 2010; Nesse and Williams 1997), we believe that introducing Tinbergen's Four Questions (Plus One) at this later point provides a few major advantages for our course. Most simply, our class includes many students who have never taken college-level biology, thus putting forth a complete model of evolutionary inquiry without working up to it may do more to confuse than to help. In addition, this model is particularly appropriate for the shift in curriculum that occurs at this time. First, Tinbergen's Four Questions (Plus One) emphasizes the way in which the mechanisms of evolution can be applied to research questions, a main focus of the Methods and Results section. Thought questions at this moment help students see how these four concerns can be treated as independent (e.g., How does this trait develop?) or as intertwined (e.g., What environmental factors does development respond to and why would this be adaptive?). We encourage them to take a similar approach while preparing their final projects. Rather than casting around for the appropriate approach to a problem, they can begin by determining which of the Four Questions (Plus One) need be invoked.

In addition, the inclusion of our fifth question sets the stage for the stronger emphasis on human-oriented in the latter portions of the course. Every module, from religion to mating and reproductive competition, will need to acknowledge the way culture may influence the traits of interest. This is obviously true when making cross-cultural comparisons or discussing behavioral tendencies that have changed during recent centuries. It is also true when presenting data from the class itself because those results cannot be independent of the culture from which they were drawn (Henrich et al. 2010). It is necessary to make explicit at the beginning of the Methods and Results section of the course that no research on modern human beings is complete without acknowledging the presence and role of cultural factors.

\section{Personality: An Example Module}

A module on human and animal personality has been a yearly part of the curriculum. Personality differences are omnipresent in daily interactions, and for this reason, some argue that including them in such a course can make the evolutionary material more accessible (Nettle 2010). It also lends itself well to each of the elements covered in Tinbergen's Four Questions (Plus One), as we summarize both below and in Table 1. Because this module has been taught multiple times with slight differences from year to year, we give a general overview of the components.

Before any material on personality is presented, the students complete an online survey that includes a measure of the Big Five personality traits (extroversion, agreeableness, conscientiousness, neuroticism, and openness to experience; Saucier 1994) and a series of life history questions (e.g., "Have you ever received a speeding ticket?"). The first class period of the module then starts with an activity. Half of the class is asked to think of species that have a general personality trait (e.g., lions are fierce, squirrels are nervous). The other half of the class is asked to identify ways in which members of the same species differ in their personalities. The lecture begins by relating these observations to ultimate mechanisms. Starting with the comments of the first group, species-specific behavioral traits are often molded by their niche. For example, prey animals need to be on guard, while predators need to be aggressive. Explaining individual differences, though, is less straightforward, and the rest of the lecture focuses on the trade-off hypothesis which proposes that when different levels of a trait entail both costs and benefits, all levels of the trait are equally fit (Nettle 2006). We illustrate using evidence from four species: bighorn sheep (e.g., Reale et al. 2000), great tits (e.g., Dingemanse et al. 2002), water striders (e.g., Eldakar et al. 2009), and humans. In light of these non-human examples, we then discuss the results from the class survey. 
The second lecture moves to Tinbergen's fourth question: phylogeny. For each of the four species, we list the major traits that were shown to have individual differences in the previous lecture and then draw parallels between these traits. For example, all four species have variations in measures that resemble extraversion (i.e., shyness-boldness) and agreeableness (i.e., social aggression or lack thereof). On the other hand, only humans have measurable variation in intellectual openness or conscientiousness. We then discuss how individual differences in each trait might evolve in response to a species' niche. Any social species will have certain costs and benefits associated with passive or aggressive responses to conspecifics. Conversely, one would expect variation in conscientiousness to be relevant only for long-lived species (i.e., with long maturational or child-rearing periods). The rest of the lecture includes examples on the roles of development and culture in understanding personality (see Table 1).

Finally, the module concludes with what is essentially a lecture on behavioral endocrinology. Though this term is used, the lecture makes clear that these are simply the proximate mechanisms that underlie behavior and, in turn, personality. The lecture begins with general examples from throughout the animal kingdom, though with a particular focus on sex hormones and aggression as this is an area of expertise for one of the authors. In the past, this has led into the work of Helen Fisher who has developed a new personality measure with four scales, each focusing on the behaviors associated with a specific hormonal or neurotransmitter system (Fisher 2009a, b; Fisher et al. 2010). Fisher is particularly interested in the role these behavioral systems play in people's preferences in romantic partners (Fisher 2009a) and interprets this from an evolutionary perspective. Her innovative but relatively simple study is presented as a model for the students' final project. We break down which of Tinbergen's Four Questions (Plus One) she is addressing and note that a few are somewhat unrelated to her interests (e.g., phylogeny). This demonstrates that while an exhaustive treatment of a topic includes all five questions, a single study need not be so comprehensive. Similarly, on the final exam, the students are asked to list which of the five questions were integral to their final project (described above) and explain how the project incorporated them.

\section{Main Advantages}

We have detailed our use of Tinbergen's Four Questions (Plus One) and the role it plays in our curriculum. Beyond our basic educational goal of teaching the application of evolutionary theory to research questions, the framework facilitates a few of our secondary goals. Namely, it successfully dispels the misguided notions underlying hyperadaptationism and genetic determinism; it permits for the reconciliation of genetic and cultural concerns under the umbrella of gene-culture coevolution; and it inclines students toward a broad question-based approach to research that transcends disciplinary boundaries.

\section{Hyperadaptationism}

One recurrent critique of the application of evolutionary theory to the study of humans - particularly research from the subdiscipline of evolutionary psychology-is the reduction of all traits to their functional adaptation. These attacks come not only from members of the social sciences who have not yet embraced an evolutionary approach (Davies 1996; Lloyd 1999) but also from other evolutionary theorists (Gould 1991; Lewontin 1998; Panksepp and Panksepp 2000; Smith et al. 2001). Likewise, some critics have pointed out that just because you can demonstrate that a trait is adaptive does not mean it is an adaptation (Laland and Brown 2002). Indeed, one of the great strengths of evolutionary theory is its unwavering rules regarding the costs and benefits associated with each trait. But, as Tinbergen's model reminds us, this is not the only consideration that an evolutionary thinker should have in mind.

Certainly, many traits, if not the vast majority of them, are adaptations whose ultimate causation is enormously enlightening, but it is short-sighted to ignore the other processes that may have contributed to its current state. Such a perspective also ignores how traits may arise that are non-adaptive (i.e., selectively neutral) or even maladaptive. We ask students to use the rest of Tinbergen's Four Questions (Plus One) to think critically about adaptationist hypotheses. The personality module provides a variety of good opportunities for this:

- Proximate explanation: Higher handgrip strength is predictive of more sexual partners in males (Gallup et al. 2007). But this is in large part because handgrip strength is governed by the testosterone system, as are many other traits that are considered physically attractive by females (Gallup and Frederick 2010).

- Phylogenetic explanation: Dodo birds were exterminated rapidly by newly arrived explorers because the absence of predators on the island of Mauritius left them with a species-specific personality lacking in fear.

- Ontogenetic explanation: Habitual aggression may seem out of place in broader society, but it can be an adaptive response to a stressful upbringing (Belsky et al. 1991).

- Cultural explanation: Plenty of behavioral tendencies that are socially learned have an adaptive value (i.e., 
bearing a fitness advantage in the local environment), but others are merely socially reinforced.

With a framework in hand that consistently reminds them of these considerations, the students are better equipped to develop non-adaptive hypotheses. In fact, many final projects exhibit this approach, and the studies designed by students usually provide a sophisticated test of adaptive value.

\section{Genetic Determinism}

Many people believe that a heritable trait implies that there is a $100 \%$ correspondence between one's genetics and the emergent phenotype. The interaction between genes and environment during trait development is relatively intuitive and can be easily explained. How it works at a proximate level, though, is a little more challenging for students to grasp. Harder still is reconciling this flexibility with adaptive traits, or, conversely, understanding how local adaption can arise despite a lack of genetic variation between individuals. Tinbergen's model lays out the pieces of the puzzle in such a way that makes the idea more accessible. Clearly, genes (the proximate factor) are most directly responsible for the products that lead to a trait. Their function seems to be conditional on environmental inputs, however (development). If one were to search for inputs that are most influential in this process, they might want to look at those features that can influence the success of one phenotype in relation to its alternatives (ultimate mechanism). In this way, the students can see how the basic threads of evolutionary inquiry can combine to explain a relatively complex phenomenon.

\section{Gene-Culture Coevolution vs. Cultural Relativism}

Gene-culture coevolution is a framework for understanding the interactions between genetic and cultural factors (Richerson and Boyd 2004). It acknowledges that genes and culture can influence each other's evolution; genes provide the raw material for culture to work with, and culture affects the environment within which genes compete. It also looks at the ways genes and culture interact during development. Proponents of the framework are careful to note that culture is not just any other environmental factor but one that is inextricably intertwined with the genetics it interacts with and influences. This singularity can be lost if cultural factors are allowed to disperse among Tinbergen's other questions; thus, it is necessary for us to introduce the new question as we incorporate gene-culture coevolution into the later parts of our course.

Apart from this curricular consideration, the relationship between culture and evolution has ideological implications.
Cultural relativists maintain that tendencies specific to a single culture should be observed only in the context of that culture and not subjected to comparisons across groups, which they fear are inherently normative (Segerstrale 2001). In a similar vein, some students see evolutionary perspectives on humans as reducing culture to mere biology and depriving it of the value and meaning that a cultural practice holds for those who adhere to it. Gene-culture coevolution, when utilized appropriately, takes note of the social processes that necessarily maintain cultural traits, allowing it to pay due respect to these aspects in addition to the psychological underpinnings of culture. Our fifth question attempts to incorporate this broadness of perspective into a model of evolutionary study.

\section{Subject-Based Interdisciplinary Research}

The research implications of a unified behavioral science are quite exciting. Breaking down the barriers between disciplines allows for the sharing of theoretical approaches, methodologies, and research designs. Most of all, it allows for a broadened perspective that takes on the subject without being limited by historical disciplinary boundaries. To illustrate, the two authors both study social behavior. Many fields have studied this topic, but each has its own starting point. Social psychologists tend to focus on contexts that influence social behavior, developmental psychologists on how individual differences in social tendencies arise, sociologists on group-level processes, economists on social attitudes during resource interactions, and so on. Each of these approaches brings its own deep literature that can easily inform the others, but only when disciplinary propriety is replaced with the pragmatic combination of all available materials to paint a complete picture of a trait.

Tinbergen's Four Questions (Plus One) gives us a practically adisciplinary model for studying a particular human-related subject. It offers a guide for categorizing the aspect of a trait that a particular study may be addressing, highlighting its utility rather than its disciplinary origin. This approach is employed by many experienced scientists, but is not necessarily a part of undergraduate, or even graduate, training. Tinbergen's Four Questions (Plus One), however, makes this approach intuitive and accessible to students from diverse backgrounds, making their approach to science flexible and increasing their potential for innovative thinking.

\section{Conclusion}

Tinbergen's Four Questions (Plus One) has proven itself to be multifaceted as a teaching technique. It clearly elucidates the different angles of an evolutionary study while also 
providing a guide for a broad research program. It can be quite useful, then, to educators pursuing either of these aims, or especially powerful when they are striving to accomplish both. We recommend it as an effective tool for all who want to bestow their students not only with the knowledge of evolutionary theory but also a heuristic for its application in daily life.

Acknowledgments This teaching technique was developed with funding assistance from the Evolutionary Studies Consortium's National Science Foundation grant (project no. 1074212).

\section{References}

Belsky J, Steinberg L, Draper P. Childhood experience, interpersonal development, and reproductive strategy: an evolutionary theory of socialization. Child Dev. 1991;62:647-70.

Book AS, Starzyk KB, Quinsey VL. The realtionship between testosterone and aggression: a meta-analysis. Aggress Violent Behav. 2001;6:579-99.

Buss D. Evolutionary psychology: the new science of the mind, vol. 3. Needham Heights: Allyn \& Bacon; 2007.

Carroll J. Literary Darwinism: evolution, human nature, and literature. Oxford: Routledge; 2004

Chang F-M, Kidd JR, Livak KJ, Pakstis AJ, Kidd KK. The worldwide distribution of allele frequencies at the human dopamine D4 receptor locus. Hum Genet. 1996;98:91-101.

Davies PS. Evolutionary theory in cognitive psychology. Mind Mach. 1996;6:445-62.

Dingemanse NJ, Both C, Drent PJ, van Oers K, van Noordwijk AJ. Repeatability and heritability of exploratory behaviour in great tits from the wild. Anim Behav. 2002;64:929-38.

Eldakar OT, Dlugos MJ, Wilcox RS, Wilson DS. Aggressive mating as a tragedy of the commons in the water strider Aquarius remigis. Behav Ecol Sociobiol. 2009;64:25-33.

Fidler AE, Van Oers K, Drent PJ, Kuhn S, Mueller JC, Kempenaers B. Drd4 gene polymorphisms are associated with personality variation in a passerine bird. Proc R Soc Lond B. 2007;274:1685-91.

Fisher H. Temperament: a biological mechanism for mate choice. Paper presented at the North Eastern Evolutionary Psychology Society; 2009a.

Fisher H. Why him? Why her? New York: Henry Holt; 2009b.

Fisher HE, Rich J, Island HD, Marchalik D. The second to fourth digit ratio: a measure of two hormonally-based temperament dimensions. Pers Indiv Differ. 2010;49:773-7.

Gallup Jr GG, Frederick DA. The science of sex appeal: an evolutionary perspective. Rev Gen Psychol. 2010;14:240-50.

Gallup AC, White DD, Gallup Jr GG. Handgrip strength predicts sexual behavior, body morphology, and aggression in male college students. Evol Hum Behav. 2007;28:423-9.

Gintis H. Five principles for the unification of the behavioral sciences. Brain Behav Sci. 2007;30:1-61.

Gould SJ. Exaptation: a crucial tool for an evolutionary psychology. J Soc Issues. 1991;47:43-65.

Henrich J, Boyd R, Bowles S, Camerer C, Fehr E, Gintis H, editors. Foundations of human sociality. Oxford: Oxford University Press; 2004.
Henrich J, Heine SJ, Norenzayan A. The weirdest people in the world. Brain Behav Sci. 2010;33:1-75.

Krebs JR, Davies NB. An introduction to behavioural ecology. 3rd ed. New York: Wiley-Blackwell; 1993.

Krebs JR, Davies NB, editors. Behavioural ecology: an evolutionary approach (4 edn). New York: Wiley-Blackwell; 1997.

Laland KN, Brown GR. Sense and nonsense: evolutionary perspectives on human behavior. London: Blackwell Science; 2002.

Lewontin RC. The evolution of cognition. In: Scarborough D, Sternberg S, editors. An invitation to cognitive science, methods, models and conceptual issues. Cambridge: MIT Press; 1998.

Lloyd E. Evolutionary psychology: the burdens of proof. Biol Philos. 1999;14:211-33.

McCracken RD. Lactase deficiency: an example of dietary evolution. Curr Anthropol. 1971;12:479-500.

Nesse RM, Williams GC. Evolutionary biology in the medical curriculum: what every physician should know. Bioscience. 1997;47:664-6.

Nesse RM, Bergstrom CT, Ellison PT, Flier JS, Gluckman P, Govindaraju DR, et al. Making evolutionary biology a basic science for medicine. Proc Natl Acad Sci. 2010;107:1800-7.

Nettle D. An evolutionary approach to the extraversion continuum. Evol Hum Behav. 2005;26:363-73.

Nettle D. The evolution of personality variations in humans and other animals. Am Psychol. 2006;61:622-31.

Nettle D. Understanding of evolution may be improved by thinking about people. Evol Psychol. 2010;8:205-28.

O'Brien DT, Wilson DS. Using "evolution for everyone" as a guide for new general education courses in evolution. J Evol Stud Consort. 2010;2:1-11.

O'Brien DT, Wilson DS, Hawley PH. "Evolution for everyone,": a course that expands evolutionary theory beyond the biological sciences. Evol Educ Outreach. 2009;2:445-57.

Odling-Smee FJ, Laland KN, Feldman MW. Niche construction: the neglected process in evolution. Princeton: Princeton University Press; 2003.

Panksepp J, Panksepp JB. The seven sins of evolutionary psychology. Evol Cogn. 2000;6:108-31.

Reale D, Gallant BY, Leblanc M, Festa-Bianchet M. Consistency of temperament in bighorn ewes and correlates with behaviour and life history. Anim Behav. 2000;60:589-97.

Richerson PJ. Culture is an active part of biology. Polit Cul. http://www. politicsandculture.org/2010/04/29/symposium-on-the-questionhow-is-culturebiological-six-essays-and-discussions-essay-4-bypeter-j-richerson-culture-is-an-active-part-of-biology/, 2010.

Richerson PJ, Boyd R. Not by genes alone: how culture transformed human evolution. Chicago: University of Chicago Press; 2004.

Saucier G. Mini-markers: a brief version of Goldberg's unipolar Big-Five markers. J Pers Assess. 1994;63:503-16.

Segerstrale U. Defenders of the truth: the sociobiology debate. Oxford: Oxford University Press; 2001.

Smith EA, Mulder MB, Hill K. Controversies in the evolutionary social sciences: a guide to the perplexed. Trends Ecol Evol. 2001;16:128-35.

Sulloway FJ. Born to rebel: birth order, family dynamics, and creative lives. London: Vintage; 1997.

Tinbergen N. On aims and methods of ethology. Z Tierpsychol. $1963 ; 20: 410-33$.

Wilson DS. Evolution for everyone. New York: Bantam Dell; 2007. 